\title{
Study on slope reinforcement effect based on FEM vegetation
}

\author{
Chang-yi $\mathrm{Yu}^{1,2,3,4}$, Ming-yue $\mathrm{Lu}^{5}$ \\ ${ }^{1}$ CCCC-Tianjin Port Engineering Institute, Ltd., 300222 Tianjin, China \\ ${ }^{2}$ CCCC First Harbor Engineering Company, Ltd., 300461 Tianjin, China \\ ${ }^{3}$ Key Laboratory of Geotechnical Engineering, Ministry of Communications, 300222 Tianjin, China \\ ${ }^{4}$ Key Laboratory of Geotechnical Engineering of Tianjin, 300222Tianjin, China \\ ${ }^{5}$ Tianjin Survey and Design Institute For Water Transport Engineering, 300000 Tianjin, China
}

\begin{abstract}
With the increasing requirements of environmental protection, the slope reinforcement method is becoming environment-friendly. In recent years, more and more attention has been paid to the study of slope reinforcement by vegetation, and the mechanism of vegetation reinforcement has been initially established, but it is not common to study vegetation reinforcement by numerical reappearance. On the basis of reviewing the mechanism of slope reinforcement by vegetation, this paper studies the vegetation reinforcement scheme of a slope by finite element method. The results show that the finite element method can be used for vegetation reinforcement simulation, and the simulation results are combined with reality. The method in this paper provides a reference for the analysis of similar problems, and also provides a reliable analysis tool for the analysis of slope reinforced by vegetation.
\end{abstract}

\section{Introduction}

With the development of western China, a large number of slopes have been excavated, which destroyed the original vegetation and shallow surface, and easily caused soil erosion, especially in plateau areas, which easily caused ecological degradation. In order to reduce the environmental damage caused by the project, vegetation reinforcement is adopted in many areas. Guo Beek et al. ${ }^{[1]}$ took the excavated slope of Shiqu-Manigango Highway as the research object, and successfully introduced the anchoring theory into the analysis of the mechanism of soil reinforcement by vegetation roots. Moreover, the effect of plant roots on slope reinforcement is mainly shallow, but the effect on deep reinforcement is not obvious. He et al. ${ }^{[2]}$ analyzed the mechanism of plant curing slope in alpine mountain area. The centrifuge model is used to simulate that the slope strengthened by vegetation can be adjusted by stress, which makes the slope form unity in hand and deformation. In the process of reinforcement, the distance between plants is the key factor for the ideal reinforcement effect. The author uses finite element method to construct the slope model strengthened by plants, and analyzes the factors affecting the slope stability in detail by combining strength reduction method. W. U. et al. ${ }^{[3]}$ classified slopes from the perspective of vegetation growth, studied the root reinforcement mechanism, and analyzed the reinforcement effects of different types of vegetation in detail by combining experimental and numerical methods. In order to maintain the stability of the slope, it is necessary to design the reinforcement method according to the actual engineering situation. $\operatorname{Yan}^{[4]}$ studied the relationship between the root model of slope vegetation reinforcement and the fractal model of root measurement. With the increase of fractal dimension, the number of roots is more, and the displacement of slope can be effectively reduced after planting in soil. The relationship between fractal dimension of plant roots and slope displacement is established. Zhong et al. ${ }^{[5]}$ carried out a large number of numerical simulations on the types and positions of vegetation on slope stability, and the results showed that planting trees at the foot of the slope and planting grass on the slope were most effective in improving slope stability. And because the weight of grass is light, its quantity has little effect on the safety factor of slope. Considering the beautification effect in the city, trees are generally planted in the middle and upper part of the slope, so it is necessary to pay attention that the slope of the slope should not be too large. In this paper, the effect of vegetation reinforcement on a slope is analyzed, and the reinforcement effect of two different vegetation at different positions is considered in the analysis.

\section{Mechanism of slope reinforcement by vegetation}

The roots of plants are widely distributed in the soil, and 
the roots are composed of vertical main roots and lateral secondary roots. Because the vertical main roots are thick and deep, the way of strengthening soil is similar to anchoring, and the way of strengthening lateral secondary roots and secondary roots of low plants is similar to reinforcement. Lateral roots and low plants have smaller diameter but larger number of roots, and their root distribution decreases and becomes thinner with the increase of soil depth. In these areas where roots are distributed, soil and plant roots can be regarded as a unified composite material ${ }^{[6]}$. Because the low roots are similar to fiber reinforcement, the theoretical mechanism of reinforcement and the stress analysis of soil stability can be analyzed according to the reinforced soil theory. When the soil is subjected to gravity and other vertical loads, the displacement changes in different directions at different positions. When the load is too large, the soil first enters into plastic deformation until it is destroyed. Because the elastic modulus of plant roots is far greater than that of soil, in order to coordinate the deformation of soil and roots, certain tensile stress will be produced in the roots to restrain the deformation. The mutual restraint between root and soil is caused by frictional shear stress, and the failure form of soil can be described by Mohr Coulomb strength criterion. From the mechanical point of view, plant roots improve soil cohesion $\Delta \mathrm{c}$, which is related to plant roots and soil properties.

Thousands of years ago, when our ancestors built city walls and made bricks, they already reinforced the soil extensively, mainly using branches, hay and other materials. The modified Mohr Coulomb strength criterion is adopted:

$$
\tau_{f}=c+\operatorname{\sigma an} \varphi+\Delta p
$$

In which $\tau_{f}$ represents the shear strength of reinforced soil, and $\mathrm{p}$ represents the shear strength of root system. Different deformations (bending and dislocation) may occur in roots at different positions. Due to the friction between soil and roots, tensile stress occurs in roots, which is composed of two forces parallel to the shear plane and perpendicular to the shear plane. The effects of these two forces are inconsistent. The component of vertical shear plane increases the confining pressure on shear plane, and the component of parallel shear plane increases the shear strength of the whole composite. Comparing the soil stress model with or without plant roots, we can study the reinforcement effect of plant roots on soil qualitatively and quantitatively ${ }^{[7]}$.

When root growth is orthogonal to shear plane:

$$
\Delta \mathrm{p}=\frac{\sum_{j=1}^{n} T_{j} \sin \theta_{j}}{A}+\frac{T \sum_{j=1}^{n} T_{j} \cos \theta_{j}}{A} \tan \varphi
$$

When the root growth is oblique to the shear plane:

$$
\begin{gathered}
\Delta \mathrm{p}=\frac{\sum_{j=1}^{n} T_{j} \sin \left(90-\varphi_{j}\right)}{A}+\frac{T \sum_{j=1}^{n} T_{j} \cos \left(90-\varphi_{j}\right)}{A} \tan \varphi \\
\varphi_{j}=\tan ^{-1}\left[1 /\left(\mathrm{k}_{j}+\left(\tan ^{-1} i_{j}\right)^{-1}\right)\right]
\end{gathered}
$$

After finishing, we can get the composite shear strength of plant roots after soil reinforcement:

$$
\begin{gathered}
\tau=c+\sigma \tan \varphi+\Delta p=c+\frac{\sum_{j=1}^{m} T_{j} \sin \theta_{j}}{A}+ \\
\frac{T \sum_{j=1}^{m} T_{j} \cos \left(90-\varphi_{j}\right)}{A}+\left(\sigma+\frac{\sum_{j=1}^{m} T_{j} \sin \theta_{j}}{A}+\right. \\
\left.\frac{T \sum_{j=m+1}^{n} T_{j} \cos \left(90-\varphi_{j}\right)}{A}\right) \tan \varphi
\end{gathered}
$$

Root system and soil constitute an anisotropic composite material, and the shear strength of soil, the contact strength between soil and root system and the tensile strength of root system determine the strength of the composite material. Generally speaking, the root system has obvious effect in strengthening soil to prevent shallow slope slip

\begin{tabular}{|c|c|c|c|c|}
\hline Material & elastic modulus/Mpa & poisson's ratio & cohesion/Pa & friction angle $/{ }^{\circ}$ \\
\hline Black cloud gneiss & 60E9 & 0.2 & 34500 & 45 \\
\hline Slag heap & $7 \mathrm{E} 6$ & 0.3 & 27500 & 24 \\
\hline
\end{tabular}

\section{Finite element model}

In this paper, the parameters of original slope are calculated according to Table 1 below. The geometric model is as shown in Figure 3, and the slope treatment is planted according to the vegetation in Fig. 1.

Table 1 Physical parameters of iron slag heap slope

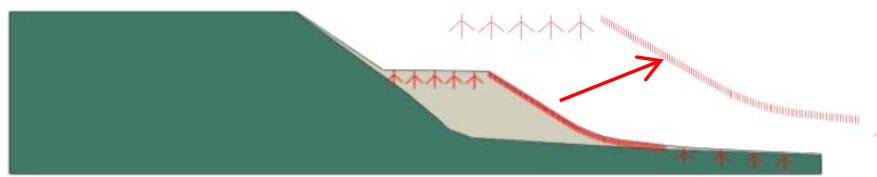

Fig. 1 Geometric model of slope reinforced by plants

There are 11056 quadrilateral elements in total. The maximum grid is $1 \mathrm{~m}$, and the vegetation adopts beam unit, and the grid spacing is $0.3 \mathrm{~m}$.

According to the vegetation requirements of the design drawings, it is assumed that the roots of the vegetation are $5-8 \mathrm{~m}$ deep in the soil, and the lateral roots are simplified into two 30-degree inclined ones. The reinforcement range of low plants such as herbs is about $1.5 \mathrm{~m}$, and there is only one vertical root system. The embedded contact algorithm in ABAQUS is adopted for the interaction between root system and soil, which does not need to divide root system and soil surface according to geometric size and set physical contact. The algorithm only needs to mesh each other, and put the embedded entity in the soil, and transfer it between the materials according to the equivalent way of nodal force, so as to realize the calculation of contact force. Has the characteristics of convenience and flexibility in operation. Vegetation-reinforced slope is simulated by embedding vegetation roots directly on the basis of original slope, ignoring loads above the surface such as tree crown. From the previous analysis, we can know that the slope 
is stable at present, and its safety factor is greater than 1. It is assumed that the safety factor of the slope after planting plants safely is still greater than 1. After trial calculation, it is found that the slope is still stable after planting plants. Strength reduction is also calculated by reducing the safety factor from 1 . Some calculation results are as follows:

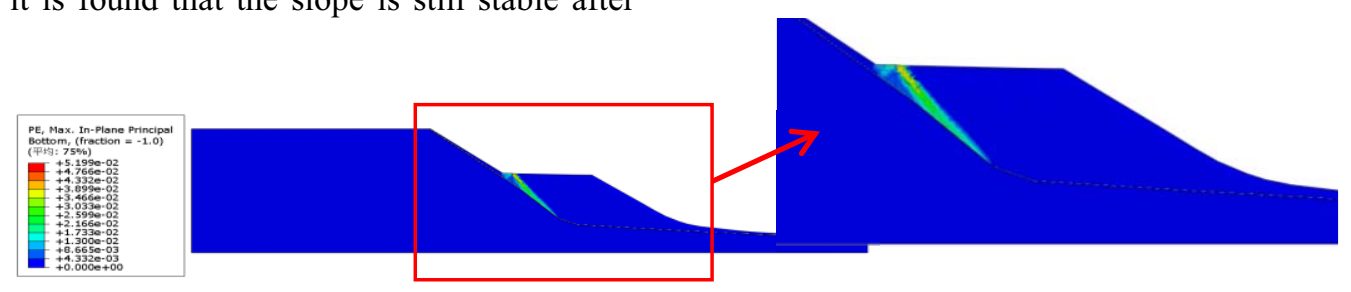

Fig. 2 Reduction factor 1.2, nephogram of slope damage

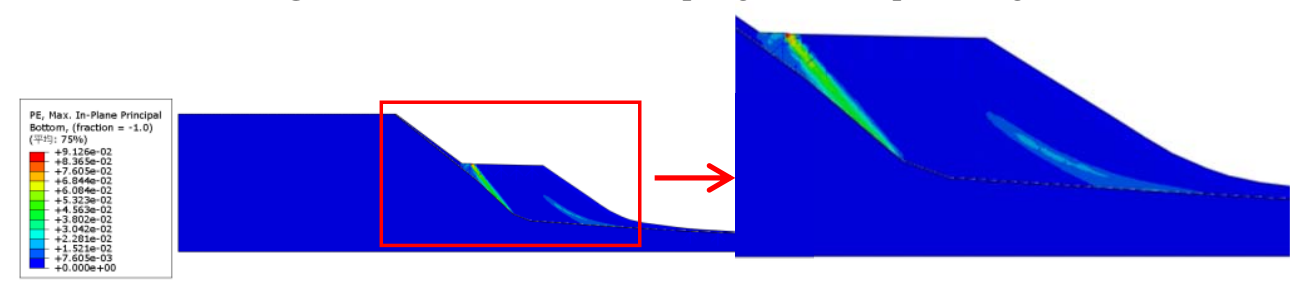

Fig. 3 Reduction factor 1.54, nephogram of slope damage

By comparing the change process of damaged area in Figure 2 and Figure 3, it can be known that shear failure occurs at the interface contact first. Subsequently, the circular slip failure of shear test occurred in the shallow slope. This is consistent with the failure results when vegetation reinforcement is not used before. It shows that vegetation reinforcement will not change the failure position and failure form of landslide. However, on the whole, vegetation has an effect on slope reinforcement, and the safety factor of slope has increased from 1.2 to 1.54. The main reason is that most of the main roots are not on the slip surface. In view of the current design, besides planting vegetation, other reinforcement measures are needed to prevent the damage of contact surface and debris flow after sliding.

\section{Conclusion}

This chapter briefly reviews the mechanical principle of slope reinforced by vegetation. On this basis, taking a slope as an example, the slope prototype and the slope reinforced by vegetation are established respectively. Through finite element strength reduction calculation, the safety factor of prototype slope and the safety factor of slope strengthened by vegetation are calculated at first. The results show that vegetation reinforcement is effective, but its effect is not obvious in the slope in this paper. The main reason is that the slope in this example is mainly cross-section friction failure, and only a small amount of vegetation roots pass through the failure surface. Therefore, the slope reinforcement in this paper should adopt other anchoring methods, such as anchor rod or anti-slide pile, which can pass through the slip plane. In addition, in the slope, it should be noted that firstly, the friction instability failure occurs at the interface between slag pile and bedrock, and then the slip failure of circular arc test occurs at the bottom cloth near the surface layer of the slope. Therefore, in the future, retaining walls or anchors can be considered to reinforce the soil surface. In addition, according to the past experience, it is not recommended to plant vegetation at the top of the slope, but to plant vegetation at the foot of the slope as far as possible, which has better reinforcement effect on the slope. This is consistent with the previous results. The analysis of different trees is not discussed in depth in this paper. But from the mechanical analysis, different kinds of trees have different roots with different depths and strengths and different distribution patterns. The reinforcement effect will be different. The root system of jujube trees is deep and thick, and its reinforcement effect is better than that of low vegetation. Therefore, this paper will not discuss in depth.

\section{References}

1. BEEK L P H V, BOGAARD T A, ASCH T W J V. Establishing the hydrological influence of vegetation on slope stability: a modelling approach in eco-engineering [J]. 2003.

2. HE J Z, HE K Q, YAN Y S, et al. Study on the Slope Stability Based on Catastrophe Theory [J]. Advanced Materials Research, 2011, 261-263.

3. BO-JIAN W U, ZHU Z D, ZU-JUN G U. Study on Accuracy of Soil Slope Stability Analysis Based on Strength Reduction FEM [J]. Journal of Water Resources \& Architectural Engineering, 2013.

4. YAN, ZX, REN, et al. Study on original ecological tridimensional slope vegetation $[\mathrm{J}]$. J $\quad \mathrm{JT}$ SCI-ENGL, 2013.

5. ZHONG Z, GUI Y, LUO S, et al. Study on Effect Mechanism of Vegetation on Slope Stability [J]. Subgrade Engineering, 2013.

6. BU Z. Effect of shallow layer of vegetation root on slope stability [J]. 2016.

7. YAN W U, ZHOU Z, ZHENG L. Study on upper bound solution of safety factor for slope stability under vegetation effect and its application [J]. Water Resources \& Hydropower Engineering, 2015. 